\title{
OS EFEITOS NATURAIS, ECONÔMICOS E SOCIAIS DA EROSÃO NA MARGEM DIREITA DO RIO SÃO FRANCISCO NA SUSTENTABILIDADE DOS AGROECOSSISTEMAS
}

\author{
Vandemberg Salvador de Oliveira - Instituto Federal Baiano - Campus Senhor do Bonfim, BA \\ vandembergsalvador@hotmail.com \\ Edison Rodrigues Barreto Júnior - Universidade Federal de Sergipe - SE - edisonbj@yahoo.com \\ Francisco Sandro R. Holanda - Universidade Federal de Sergipe - SE - fholanda@infornet.com.br
}

\section{RESUMO}

A evolução do processo erosivo na margem direita do baixo curso do rio São Francisco tem ocorrido de forma acentuada e os vários estudos que foram desenvolvidos para determinar os processos de degradação ambiental convergem para um ponto comum: o processo erosivo marginal foi intensificado a partir da regularização da vazão do rio, através da implantação das barragens. Essa intervenção no curso natural do rio tem causado prejuízos ambientais, econômicos e sociais. Este trabalho teve por objetivo levantar a linha atual da margem direita do rio São Francisco, quantificar a perda de área agricultável nos agroecossistemas e analisar os seus efeitos na sustentabilidade dos agroecossistemas implantados no Perímetro Irrigado Cotinguiba/Pindoba. Utilizando-se a tecnologia de posicionamento por satélite - GPS (Global Positioning System) para o levantamento da posição da margem atual e mapas topográficos do Mapeamento Sistemático Nacional - editados em 1975, foi possível determinar o recuo da margem e a área agrícola erodida. A média anual do recuo da margem mede 12,36 metros. A área agrícola perdida corresponde a uma superfície equivalente a 75,59 hectares. Esta superfície agricultável representa $2,5 \%$ da área total do projeto de irrigação Cotinguiba/Pindoba e a perda por erosão é da ordem de 3,0 hectares/ano.

Palavras-chave: degradação ambiental; erosão marginal; externalidades; custo marginal social; eficiência da produção.

\section{THE EFFECTS OF NATURAL, ECONOMIC AND SOCIAL EROSION IN THE RIGHT MARGIN OF RIVER SÃO FRANCISCO IN THE SUSTAINABILITY OF AGROECOSYSMS}

\section{ABSTRACT}

The evolution of the erosion on the right bank of the lower course of the São Francisco river has occurred dramatically and the various studies conducted to determine the environmental degradation converge at a common point: the marginal rate of erosion was intensified after the regularization river flow, through the deployment of the dams. This intervention in the natural course of the river has caused ecological damage, economic and social. This study aimed at assessing the current row of the right bank of the river São Francisco, to quantify the loss of arable land in agroecosystems and analyze their effects on the sustainability of agroecosystems deployed in the irrigated Cotinguiba / Pindoba. Using the technology of satellite positioning - GPS (Global Positioning System) to survey the current position of the bank and topographical maps of National Systematic Mapping - published in 1975, it was possible to determine the margin retreat and farmland eroded. The average annual retreat of the margin measures 12.36 meters. The agricultural area lost corresponds to an area of 75.59 hectares. This area is arable $2.5 \%$ of the total area of the irrigation project Cotinguiba / Pindoba and loss by erosion 
is about 3.0 hectares per year.

Key-words: environmental degradation, riverbank erosion, externalities, social marginal cost, efficiency of production.

\section{INTRODUÇÃO}

A degradação ambiental pode ter uma série de causas, dentre elas é comum colocar-se a responsabilidade no crescimento populacional e, na conseqüente pressão exercida sobre o meio físico. O manejo inadequado do solo, tanto em áreas urbanas, como nas em áreas rurais, é a principal causa da degradação (Blackie \& Brookfield, 1987). Segundo Brady (1989), nenhum outro fenômeno de solo é mais destrutivo em âmbito mundial do que a erosão, que abrange perdas de água e de nutrientes em ritmos muito elevados. Além disso, o solo removido desloca-se para rios e lagos e aí se transforma em problema de poluição.

Do ponto de vista agrícola, Ferreira (1979), Amaral (1986) e Porto (1986) entre outros, definiram a erosão como sendo a desagregação e o arrastamento das partes constituintes do solo, através da ação da água ou do vento. Para Cunha \& Guerra (2000), à medida que a degradação ambiental é acelerada e se expande espacialmente numa determinada área que esteja sendo ocupada e explorada pelo homem, a sua produtividade tende a diminuir, a menos que o homem invista no sentido de recuperar essas áreas.

Suguio (1998) atribui a aceleração do fenômeno erosivo, principalmente à ação antrópica, através do desmatamento que introduz várias modificações no ciclo hidrológico e, portanto, no ciclo de erosão, causando conseqüentemente o decréscimo das áreas agricultáveis.

A erosão fluvial é causada pelas águas dos rios, principalmente nas épocas de cheias, podendo, em alguns casos, ocasionar a destruição das margens de rios por desmoronamento ou escorregamento (Guidicini \& Nieble, 1983). A erosão fluvial nas margens e no leito transporta os sedimentos incoesivos (areias) partícula por partícula, enquanto que os coesivos (sílticoargilosos) podem ser carreados em porções maiores originadas por solapamento da base e colapso das margens (Leinz \& Amaral, 1998).

A erosão marginal, como componente da erosão fluvial, destrói as margens dos rios, desempenhando um importante papel no controle da largura do canal dos mesmos. Este tipo de erosão contribui significativamente no incremento da carga de fundo dos rios, e provoca destruição progressiva da área marginal desvalorizando os terrenos ribeirinhos e limitando o seu uso adequado (Thorne \& Tovey, 1981).

A evolução do processo erosivo na margem direita do baixo curso do rio São Francisco tem ocorrido de forma acentuada, conforme os vários estudos que foram desenvolvidos para determinar os processos de degradação ambiental e as suas conseqüências em curso, dentre eles podem-se citar: Casado (2000), que monitorou o processo erosivo na margem direita e seus efeitos no perímetro irrigado Cotinguiba/Pindoba; Santos (2001), estudou a destruição da vegetação ciliar como causa e conseqüência do processo erosivo; Santos (2002), avaliou a estabilidade dos taludes marginais e seus movimentos; Fontes (2002), analisou a erosão marginal e seus aspectos geomorfológicos e Bandeira (2005), discorreu sobre a evolução do processo erosivo e a eficiência dos enrocamentos no seu controle da erosão, todos corroborando que o processo erosivo marginal foi intensificado a partir da regularização da vazão do rio pela implantação das barragens.

Ross (2000), considera que as pesquisas básicas associadas à erosão são fundamentais tanto para as práticas agrícolas, como para subsidiar o planejamento ambiental, como suporte quantitativo à análise até então feita de forma qualitativa para a fragilidade dos ambientes naturais.

A mensuração do processo de recuo da margem no baixo São Francisco sergipano 
e as suas conseqüências degradacionais nos diversos agroecossistemas ali implantados, consubstancia-se numa informação essencial no sentido de paramentrizar e avaliar o potencial da sua amplitude, considerando que este componente - a erosão marginal - interfere na sustentabilidade das áreas de produção dos projetos de irrigação Cotinguiba/Pindoba, à medida que vem causando degradação do solo e destruindo a sua infra-estrutura física, tornando-se um fator de desestabilização ambiental, econômica e social.

\section{Agroecossistemas, erosão marginal e sustentabilidade}

Segundo Hart (1980) o agroecossistema é um ecossistema com presença de pelo menos uma população agrícola, portanto pode ser entendido como uma unidade de trabalho no caso de sistemas agrícolas, diferindo fundamentalmente dos ecossistemas naturais por ser regulado pela intervenção humana na busca de um determinado propósito.

Os agroecossistemas, de modo genérico, podem ser divididos em três tipos: aqueles que apresentam um subsistema culturas, os constituídos por um subsistema animal e os que possuem um subsistema com espécies vegetais e animais. Há ainda outros tipos de agroecossistemas: os aquáticos, os florestais, os agroflorestais, os silvopastorais e os agrossilvopastorais (Hart, 1980).

Na definição conceitual de Schlindwein \& D’Agostini (1998) sobre agroecossistemas, é necessário que sejam reconhecidas três dimensões: a dimensão física, representada pelo espaço físico e pelo conjunto das populações neles circunscritas; a dimensão funcional caracterizada pelas relações que se estabelecem entre a dimensão física e o meio circunvizinho e a dimensão conjuntural.

Os estudos sobre sistemas de produção conduzem à tarefa inicial de identificar, localizar e delimitar os sistemas com culturas e/ou animais existentes em determinada região. A identificação implica no conhecimento das espécies vegetais e/ou animais componentes do arranjo espacial e as possíveis interações entre elas. Na localização procura-se estabelecer a relação entre os sistemas de produção existentes e as áreas geográficas em que estão situados e a delimitação efetiva do sistema de produção ou agroecossistemas, sendo determinadas à extensão da área ou áreas ocupadas.

Segundo Fontes (2002) a erosão das margens no baixo curso do rio São Francisco é uma das manifestações mais visíveis do complexo reajustamento da morfologia do canal em busca de um novo equilíbrio dinâmico e das alterações do sistema fluvial, assumindo proporções maiores em dois trechos da margem direita, onde estão localizados os projetos de irrigação Cotinguiba-Pindoba e Betume.

O Perímetro Irrigado Cotinguiba/Pindoba foi implantado em 1980, às margens do rio São Francisco, no seu baixo curso, pela Companhia de Desenvolvimento do Vale do São Francisco - CODEVASF - e entrou em operação a partir de 1981. Ele ocupa uma superfície equivalente a 3.083 hectares, dos quais 2.215 hectares de áreas irrigadas e 300,00 hectares para agricultura de sequeiro. Os 2.215 hectares de área irrigada estão subdivididos em 1.117 hectares com irrigação por inundação destinados à cultura de arroz e 1.098 hectares irrigados pelo método de aspersão, destinados à policultura (hortaliças, frutíferas e grãos e pecuária) (Codevasf, 1998).

A margem direita do Baixo São Francisco vem sofrendo desgaste superficial devido à ocorrência de processos erosivos, o que vêm ameaçando as estruturas da engenharia de proteção contra as cheias dos perímetros irrigados e também as demais localidades situadas no entorno próximo às áreas atingidas (Codevasf, 2000).

Para Fonseca \& Bastos (1998) as intervenções sofridas pelo rio a partir da construção 
das barragens são fruto de um modelo de desenvolvimento que "desconsiderou os custos sociais e ambientais", deixando às expensas da sociedade os custos marginais sociais decorrentes das externalidades provocadas pela implantação das barragens, entre elas o aumento do processo erosivo e a degradação das áreas agricultáveis".

À medida que a degradação ambiental é acelerada e se expande espacialmente numa determinada área que esteja sendo ocupada e explorada pelo homem, a sua produtividade tende a diminuir, a menos que o homem invista no sentido de recuperar essas áreas (Cunha \& Guerra, 2000).

Para Casado (2000) "no Baixo São Francisco sergipano os efeitos relacionados ao processo de desmatamento da vegetação ciliar e à modificação da calha do rio em função da construção das barragens têm provocado a diminuição das áreas agricultáveis e se acentuado superlativamente nos últimos anos, potencializando ainda mais os processos erosivos", no Perímetro Irrigado Cotinguiba/Pindoba.

Em função da sua localização - às margens do rio São Francisco - os agroecossistemas implantados no Perímetro Irrigado Cotinguiba/ Pindoba sofrem os efeitos diretos da erosão marginal, que diminui continuamente a superfície agricultável destes agroecossistemas à medida que provoca impactos ambientais e sócio-econômicos negativos solapando sustentabilidade desses agroecossistemas.

Os efeitos da perda de áreas agrícolas provocados pela erosão fluvial marginal sobre os agroecossistemas devem ser mensurados no sentido de avaliar a pressão que este impacto ambiental produz no meio físico, enquanto vetor de degradação e desequilíbrio natural e sócioeconômico.

Segundo Hooke (1980) existem três principais fontes de informações utilizadas no estudo da velocidade de recuo das margens fluviais: medições diretas no campo, para período de um a dez anos; comparação de mapas antigos e fotografias aéreas em diferentes datas, para um período de dez a duzentos anos; e a utilização de evidências biológicas e sedimentares datáveis, para um período de trinta a quinhentos anos.

A atual posição da linha de margem do rio é também passível de definição em campo, através da tecnologia de posicionamento por satélite, no sistema denominado Global Positioning System - GPS, e a linha pretérita da margem pode ser definida a partir de mapas topográficos do mapeamento sistemático nacional, georreferenciados, possibilitando análises multitemporais com precisão e celeridade.

A partir de uma análise multitemporal compreendendo o período de 1975 a 2005, este trabalho teve por objetivo levantar a linha atual da margem direita do rio São Francisco e quantificar a perda de área nos agroecossistemas, o recuo da margem provocado pela erosão marginal, assim como, implantar uma rede de marcos georreferenciados nos três sítios experimentais onde são desenvolvidas as pesquisas sobre erosão fluvial pelo Grupo de Pesquisa em Gestão Hidroambiental do Baixo São Francisco.

\section{MATERIAL E MÉTODOS}

\section{Localização da área estudada}

A área da pesquisa está localizada no baixo curso do rio São Francisco, na sua margem direita, em um trecho compreendido entre as coordenadas UTM: $\mathrm{N}=8870.600 \mathrm{~m}$ e $\mathrm{N}=8868.000 \mathrm{~m}$ e as coordenadas $\mathrm{E}=736.000 \mathrm{~m}, \mathrm{E}=745.000 \mathrm{~m}$, no município de Propriá, estado de Sergipe. O trecho monitorado tem início na ponte sobre o rio São Francisco - que interliga os estados de Sergipe e Alagoas - e o término no sítio experimental $n^{\circ} 03$, situado à jusante da ponte, cuja extensão mede 6.300 metros.

A escolha deste trecho está relacionada a alguns aspectos considerados fundamentais, a saber: a acelerada erosão ocorrente na área compreendida entre o município de Propriá e a foz do rio São Francisco; a localização de vários agroecossistemas já atingidos pelo processo erosivo; a necessidade de quantificar as áreas 
atingidas pela erosão fluvial, enquanto dado essencial para o diagnóstico e a proposição de medidas mitigadoras; a necessidade de implantação de bases (marcos) georreferenciados, para garantir o monitoramento sistemático da erosão a partir de coordenadas precisas nos três sítios experimentais instalados para pesquisas da erosão fluvial.

\section{Coleta de dados no campo}

As campanhas de campo foram efetuadas no período de julho de 2005 a abril de 2006, com equipe composta por três auxiliares e um técnico. Utilizaram-se os seguintes recursos: um veículo, quatro receptores PROMARK2®, quatro antenas geodésicas, dois tripés, dois adaptadores para antena, dois bastões, um computador, o software de pós-processamento ASHTECH SOLUTION $®$ e o Sistema de Automação Topográfica DATAGEOSYS®.

Foram trabalhados três sítios experimentais, assim descritos:

a) Sítio $n^{\circ} 01$ - Este sítio experimental vem sendo monitorado desde 2001 (Holanda et al. (2005), Santos (2002) e Bandeira (2005)), e nele se encontra instalado um experimento para contenção da erosão marginal por meio de implantação de biotêxtil e recuperação da vegetação ripária. Localizado na margem direita do rio São Francisco, cujas coordenadas UTM são $\mathrm{E}=744.316,102$ e $\mathrm{N}=8868.464,033$, este sítio experimental possui uma área de $888,05 \mathrm{~m}^{2}$, com largura média em torno de 6,34 metros; a altura média do barranco de 2,63 metros e comprimento de 100,00 metros. Apresenta declividade média de $43,03 \%$. É formado por material coesivo (silte e argila) e incoesivo (areia), com cobertura vegetal predominantemente formada por gramíneas e espécies de folhas largas, em processo de sucessão natural.

b) Sítio $n^{\circ} 02$ - Este sítio experimental vem sendo monitorado desde julho de 2005 (Bandeira, 2005). Localizado na margem direita do rio São Francisco com Coordenadas UTM E= $739.072,654 \mathrm{~m} \mathrm{e} \mathrm{N}=8869.745,944 \mathrm{~m}$, possui uma área de $1.073,87 \mathrm{~m}^{2}$, com largura média em torno de 10,01 metros; a altura média do barranco de 4,03 metros e comprimento de 100,00 metros, com declividade média de 40,95\%. É formado essencialmente por material coesivo (argila) e não apresenta cobertura vegetal.

c) Sítio $n^{\circ} 03$ - Este sítio experimental passou a ser monitorado pelo Grupo de Pesquisa em Gestão Hidroambiental do Baixo São Francisco desde julho de 2005, cujas coordenadas UTM são Coordenadas UTM E=744.705,003 e $\mathrm{N}=8868.410,997 \mathrm{~m}$. Localizado na margem direita do rio São Francisco possui uma área de $657,90 \mathrm{~m}^{2}$, com largura média em torno de 5,90 metros; a altura média do barranco mede 3,49 metros e comprimento 100,00 metros. Apresenta declividade média de $63,64 \%$. É formado essencialmente por material incoesivo (areia) e não apresenta cobertura vegetal.

\section{Base e parâmetro de exatidão cartográfica e descrição do método de rastreio}

A linha de margem no ano de 1975 foi extraída a partir da Carta Topográfica 635 2-3, executada na escala 1: 25.000, contendo informações sobre hidrografia, uso e ocupação do solo, malha fundiária e obras de infra-estrutura, cujas coordenadas geográficas medem $10^{\circ} 12^{\prime} 30^{\prime}$ ' e $10^{\circ} 25^{\prime} 00^{\prime \prime}$ de latitude sul e $36^{\circ} 40^{\prime} 00^{\prime \prime}$ e $36^{\circ} 52^{\prime} 30^{\prime \prime}$ de longitude oeste, referidas ao equador e ao meridiano de Greenwich, respectivamente, digitalizada em scanner profissional marca MICROTEK $\AA$, modelo SCANMAKER ${ }^{\circledR} 9800$ XL e georreferenciada utilizando-se o Sistema de Análise Geoambiental SAGA/UFRJ. Os parâmetros cartográficos utilizados para se obter a padronização paramétrica da área mapeada foram o sistema de projeção Universal Transversa de Mercator-UTM e o Datum Horizontal SAD 69.

O levantamento da posição atual da linha de margem foi realizado com equipamento dotado de tecnologia GPS. O equipamento utilizado foi um receptor geodésico marca ASHTECH $\AA$, modelo PROMARK2®, de 12 canais independentes, com precisão horizontal Estática de 0,005m + 1 ppm; Cinemática de $0,012 \mathrm{~m}+2,5 \mathrm{ppm}$ e Stop\&Go igual a $0,010 \mathrm{~m}$ 
+ 1,5 ppm destinado, dentre outras funções, a de coletar dados para levantamentos terrestres de apoio de campo, nas escalas de mapeamento sistemático, em modo diferencial.

Utilizou-se como base primordial no transporte das coordenadas para a área da pesquisa, omarconúmeron ${ }^{\circ} 05-\mathrm{SCR}$, implantado pela SEPLANTEC no Campus da Universidade Federal de Sergipe. No ponto base (MARCO$05 \mathrm{SCR}$ ), trabalhou-se com dois equipamentos de rastreio, um pela manhã e outro à tarde. A adoção desta rotina objetivou evitar a perda de dados por saturação de memória do receptor. A técnica escolhida para a determinação das coordenadas do ponto rastreado foi diferencial pós-processado. A partir do ponto base (marco 05-SCR), foi implantado um marco denominado MBASE, próximo à ombreira esquerda da ponte sobre o rio São Francisco, na margem esquerda da rodovia $\mathrm{BR}-101$.

Após o pós-processamento dos dados obtidos no rastreio e conhecidas as coordenadas precisas do marco (MBASE), este passou a ser ocupado como "base" para o levantamento da margem atual do rio São Francisco e para a implantação dos marcos georreferenciados nos sítios experimentais 01,02 e 03.

$\mathrm{O}$ rastreio das coordenadas da margem do rio foi efetuado por caminhamento no modo cinemático, com o receptor denominado "rover", simultaneamente ao da base, armazenando-se as coordenadas. A necessidade da coleta simultânea é para se poder aplicar a técnica de correção diferencial. Esta técnica envolve a colocação de uma base contendo um receptor em local com coordenadas conhecidas e precisas (MBASE), coletando dados simultaneamente com outros receptores "rover" (Incra, 2001).

\section{Processamento dos dados}

Os dados coletados pelo "rover" foram transferidos para um microcomputador Pentium ${ }^{\circledR} 4$ para pós-processamento, utilizando-se $\mathrm{o}$ software ASHTECH SOLUTION®. Após o pósprocessamento dos dados de campo, eles foram exportados em formato DXF (Drawing Exchange Format) para o software DATAGEOSYS $\AA$, para o cálculo de área erodida e as distâncias do recuo da margem, a partir das coordenadas dos vértices da poligonal.

No mapa do levantamento da área elaborado na escala de 1:25. 000, a área erodida é formada pelas poligonais da margem no ano de 1975 e a linha de margem atual e foram obtidas a partir da seleção das coordenadas dos vértices, no software comercial de automação topográfica DATAGEOSYS $®$.

\section{RESULTADOS E DISCUSSÃO}

\section{Recuo da linha de margem}

A partir do levantamento topográfico executado em 2005, empregando-se tecnologia GPS, foi possível avaliar o recuo da linha da margem, a superfície de área agrícola destruída pelo processo erosivo e as distâncias do recuo da margem no trecho pesquisado, cuja extensão mede 6.300 metros. Além disso, foi implantada uma rede de marcos georreferenciados nos três sítios experimentais que estão inseridos nessa faixa pesquisada.

Foi constatado que o recuo da margem é variável, com valores entre 309,15 metros (maior distância) e 12,26 metros (menor distância). Esta variabilidade observada nas distâncias do recuo está relacionada a morfometria do canal, a declividade e o tipo de solo da margem (coesivo ou incoesivo) e a ausência de vegetação ciliar ou ripária. Para Thorne (1978) dentre os fatores que condicionam a erosão nas margens fluviais, destacam-se a altura, a geometria e a estrutura do barranco, as propriedades mecânicas do material, as características hidrológicas do fluxo nas proximidades da margem e as condições climáticas. Conforme Ross (2000), o grau de proteção por tipos de cobertura vegetal é muito baixo ou nulo em áreas desmatadas.

No ponto de maior recuo da margem $(309,15 \mathrm{~m})$, além da proximidade com o eixo do rio, o barranco encontra-se exposto, sem cobertura vegetal e a declividade é superior 
a $60 \%$. Considerando que uma declividade superior a $30 \%$ compõe uma categoria muito forte e suscetível a erosão (Ross, 2000), a margem neste ponto pode ser classificada como de altíssima fragilidade. A média anual do recuo da margem neste ponto mede 12,36 metros e a mensal 1,03 metros, considerando o período estudado de 25 anos.

Fernandez (1990) citado por Holanda et. al. (2005), pesquisou a erosão marginal no rio Paraná e encontrou uma taxa média de recuo da ordem de 0,6 a 0,7 metro/mês. A média geral dos recuos encontrada neste estudo, na faixa levantada de 6.300 metros, durante 25 anos, mede 123,17 metros e corresponde a uma taxa de erosão marginal anual é de 4,10 metros, que perfaz a média mensal de 0,34 metro.

A variação nas condições morfométricas do barranco, do solo e da vegetação da margem no trecho estudado, se reflete na amplitude das médias diferenciadas, principalmente quando se considera a extensão do trecho desta pesquisa 6.300 metros. A abrangência temporal avaliada neste estudo, em comparação com os estudos anteriores, é um fator diferencial que concorre efetivamente para as diferenças encontradas.

\section{Monitoramento da erosão marginal}

O monitoramento da erosão marginal, realizado para a presente pesquisa, através de levantamento topográfico, utilizando tecnologia GPS, em relação com o método das perfilagens sucessivas (Holanda et al., 2005), forneceram resultados que consideraa celeridade na execução, a precisão do método, as extensões que podem ser monitoradas em curto espaço de tempo e a possibilidade de monitoramento continuado, a partir das coordenadas determinadas.

A área agrícola erodida na margem corresponde a uma superfície equivalente a $755.99 \mathrm{~m}^{2}$ ou 75,59 hectares. Esta superfície agricultável representa $2,5 \%$ da área total do projeto de irrigação Cotinguiba/Pindoba e corresponde a 3,0 hectares/ano de terra irrigável que são perdidos por erosão marginal nos agroecossistemas.
De acordo com a CODEVASF (1984), a estrutura fundiária na região do Baixo São Francisco, que compreende os estados de Sergipe e Alagoas, possui mais de 50\% dos estabelecimentos com áreas inferiores a 5,0 hectares. As atividades econômicas desenvolvidas nessa região (agricultura de sequeiro e pecuária extensiva), utilizam tecnologia inadequada ao tamanho das propriedades, o que resulta na ausência de sustentabilidade econômica e social para a população. Este fato evidencia a gravidade e a significância da perda de 3,0 hectares/ano de área cultivável, que poderia ser explorada satisfatoriamente a partir da disponibilização de toda infra-estrutura de irrigação disponível para produção agrícola e pecuária nos agroecossistemas implantados no Perímetro Irrigado Cotinguiba/Pindoba.

De acordo com Cunha \& Guerra (2000) à medida que a degradação ambiental é acelerada e se expande numa determinada área que esteja sendo ocupada e explorada pelo homem, a sua produtividade tende a diminuir, a menos que o homem invista no sentido de recuperar essas áreas afetadas. Sobre a alocação de investimentos para a recuperação de áreas degradadas, no caso da degradação ambiental causada por erosão marginal que extingue as áreas exploradas pelos agroecossistemas, a recuperação dessas áreas atingidas pela erosão marginal no Perímetro Irrigado Cotinguiba/Pindoba não é possível, independente do investimento alocado para recuperá-las, visto que o material erodido é transportado para o canal do rio e fica, portanto, submerso.

Avaliando-se a superfície da área suprimida pela erosão marginal, constata-se que a sustentabilidade dos agroecossistemas instalados no Perímetro Irrigado Cotinguiba/ Pindoba está comprometida, considerando-se que a expansão da erosão marginal, que causa a degradação ambiental sistêmica nas áreas agrícolas, requer investimentos cada vez maiores no sentido de apenas mitigar o impacto negativo da degradação e não recuperá-las. Neste caso, em que as condições de recuperação são suprimidas 
pelas externalidades provocadas continuamente a partir da construção das barragens, resta apenas a opção de mitigar os efeitos dessa externalidade, uma vez que as mudanças no ciclo hidrológico do rio alteraram e alteram o ciclo de erosão marginal, que agora é controlado pelas enchentes sazonais.

O elevado valor encontrado de 3,0 ha/ ano na perda de superfície dos agroecossistemas implantadosnafaixamarginal dorio SãoFrancisco, no trecho pesquisado, demonstra a necessidade e a importância dos estudos locacionais na implantação e operação dos agroecossistemas, pois é nesta fase que se procura estabelecer a relação entre os sistemas de produção e as áreas geográficas em que serão situados. A localização do perímetro irrigado Cotinguiba/Pindoba em um trecho sedimentar composto por solos como Neossolos Flúvicos de baixa coesão e com espessas camadas predominantemente arenosas, concorre efetivamente para a sua degradação por erosão marginal e os efeitos dessa externalidade provocada pela construção das barragens afetam contínua e sistematicamente a sustentabilidade dos agroecossistemas implantados.

Adeterminaçãodascoordenadasdaestaçãode base (MBASE) nas proximidades da faixa estudada e a implantação dos marcos georreferenciados nos sítiosexperimentais,possibilitarãoomonitoramento sistemático nos estudos posteriores, a partir dos marcos implantados nos sítios experimentais e do registro das coordenadas da margem atualmente. As análises multitemporais e sistematizadas, poderão ser efetuadas a partir de uma tecnologia amplamente utilizada - GPS - em diversos segmentos de pesquisas ambientais e agrícolas, consubstanciando-se método e técnica, satisfatórios e apropriados para estudos desta ordem.

\section{CONCLUSÕES}

O impacto provocado pela erosão fluvial compromete a sustentabilidade ambiental, econômica e social dos agroecossistemas existentes na margem do rio São Francisco, impossibilitando definitivamente $o$ aproveitamento da área para fins agro-pastoris.

A erosão marginal em muitos trechos da margem do rio se configura como um impacto irreversível e permite apenas medidas de atenuação, diferentemente de alguns impactos provocados pela erosão pluvial.

O processo de erosão é potencialmente degradador nos agroecossistemas implantados próximos à margem do rio, atingindo as áreas cultivadas e as obras de infra-estrutura importantes, podendo atingir os canais de irrigação e outras obras estruturantes dos projetos de irrigação.

A média anual do recuo, no trecho mais avançado, é de 12,4 metros.

A área agricultável perdida por erosão no período analisado é cerca de 2,5\% da área total do Perímetro Irrigado Cotinguiba/Pindoba e corresponde a uma superfície de 3,0 ha/ano de supressão de espaço potencialmente explorável pelos agroecossistemas.

Os efeitos dessa externalidade negativa a erosão - precisam ser mensurados e analisados urgentemente, considerando que interfere de forma direta não apenas na sustentabilidade ambiental, mas também, no que se refere ao equilíbrio social e econômico dos ribeirinhos. Conhecer o custo marginal social e o grau de eficiência da produção de energia a partir da construção das barragens é condição "sine qua non" para que se possa estabelecer padrões de sustentabilidade e equilíbrio tridimensionais ambiental, econômico e social.

O monitoramento da erosão marginal realizado com tecnologia GPS evidenciou a celeridade, a precisão do método e a amplitude das extensões que podem ser mapeadas e descritas com esta ferramenta.

\section{REFERÊNCIAS BIBLIOGRÁFICAS}

AMARAL, N.D. Noções de conservação do solo. 2.ed. São Paulo: Nobel, 1986. 120 p.

BANDEIRA, A.A. Evolução do Processo Erosivo na Margem Direita do Rio São Francisco e Eficiência dos Enrocamentos no 
Controle da Erosão no Trecho em Estudo.

Dissertação (Mestrado em Desenvolvimento e Meio Ambiente) - Núcleo de Pós-graduação e Estudos do SemiÁrido, Universidade Federal de Sergipe. São Cristóvão, SE, 2005.

BRADY, N. C. Erosão do solo e seu controle. In: Natureza e propriedades dos solos. Traduzido por Antônio B. Neiva Figueiredo Filho. 7.ed. Rio de Janeiro: Freitas Bastos, 1989.

BLAICKIE, P., BROOKFIEL, H. Land degradation and society. Inglaterra: Methuen Ltda,1987.

CASADO, A.P.B. Estudo do processo erosivo na margem direita do rio São Francisco:

Perímetro irrigado Cotinguiba/Pindoba Baixo São Francisco Sergipano. Dissertação (Mestrado em Desenvolvimento e Meio Ambiente) - Núcleo de Pós-graduação e Estudos do SemiÁrido, Universidade Federal de Sergipe. São Cristóvão, SE, 2000.

CODEVASF. Ficha técnica do perímetro Cotinguiba/Pindoba. Aracaju: CODESVASF, 1998. 13p.

CODEVASF. Incidência de desmoronamento das barrancas do rio São Francisco na faixa de domínio do perímetro irrigado Cotinguiba/ Pindoba. Brasília: CODEVASF, 2000, 13p.

CUNHA, S.B.; GUERRA, A.J.T. - Degradação Ambiental. In: CUNHA, S.B.; GUERRA, A.J.T. (orgs.). Geomorfologia e Meio Ambiente. Cap.7, p.337-347.Rio de Janeiro: Ed.Bertrand Brasil, 2000.

FERNANDEZ, O.V.Q. Mudanças no canal fluvial do rio Paraná e processos de erosão nas margens região de Porto Rico, PR. Rio Claro, 1990. IGCE. ENESP. Dissertação (Mestrado em Geociências).86 p.

FERREIRA, P.H.M. Erosão. In: Princípios de manejo e de conservação do solo. São Paulo:
Nobel, 1979. p. 57-70.

FONTES, L.C.S. Erosão marginal associada a impactos ambientais a jusante de grandes barragens: $O$ caso do baixo curso do rio São Francisco. Dissertação (Mestrado em Desenvolvimento e Meio ambiente) - Programa de Pós-graduação em Desenvolvimento e Meio Ambiente (PRODEMA), Universidade Federal de Sergipe, São Cristóvão, 2002.

FONSECA, V. \& BASTOS, E. A. Sertão do Baixo São Francisco Sergipano: Bacia Hidrográfica como unidade de estudo. Aracaju: UFS/CODEVASF, 1997.

GUIDICINI, G.; NIEBLE C.M. Estabilidade dos taludes naturais e de escavação. São Paulo: Edgard Blücler, 1983. 194 p.

HART, R.D. Agrosistemas; conceptos básicos. Turrialba, CATIE, 1980, 211p.

HOOKE, J.M. Magnitude and distribution of rates river bank erosion. Earth surface processes. V.5, p.143-157.1980.

HUGHES, D.J. Rates of erosion on meandearcs. In: River channel changes. John Wiley ans Sons, Ins. 1977, p.193-205.

INCRA. Normas Técnicas para Levantamentos Topográficos. Brasília, 2001.

LEINZ, V.; AMARAL, S.S. Geologia Geral. 3.ed. São Paulo: Editora Nacional, 1998.

PORTO, R.P. A erosão dos solos no Rio Grande do Sul. In: Política e meio ambiente. Porto Alegre: Mercado Aberto, 1986. p.49-55.

ROSS, J.L.S. Geomorfologia Aplicada aos EIAs RIMAs. In: CUNHA, S.B.; GUERRA, A.J.T. (orgs.). Geomorfologia e Meio Ambiente. Cap.6, p.323. Rio de Janeiro: Ed.Bertrand Brasil, 2000. 
SANTOS, L.G.C. Diagnóstico dos remanescentes da mata ciliar no Baixo São Francisco Sergipano afetado pela erosão marginal e a compreensão dos ribeirinhos sobre a degradação desta vegetação. Dissertação (Mestrado em Desenvolvimento e Meio Ambiente) - Núcleo de Pós-graduação e Estudos do Semi-Árido, Universidade Federal de Sergipe. São Cristóvão, SE, 2001.

SANTOS, C.M. A erosão no Baixo São Francisco Sergipano e os mecanismos de desestabilização dos taludes na margem do rio. 2002. Dissertação (Mestrado em Desenvolvimento e Meio ambiente) - Programa de Pós-graduação em Desenvolvimento e Meio Ambiente (PRODEMA), Universidade Federal de Sergipe, São Cristóvão, 2002.
SCHLINDWEIN， S.L.; D'AGOSTINI， L.R. Sobre o Conceito de Agroecossistemas. Florianópolis: UFSC, 1998. p.18.

SUGUIO K. Dicionário de geologia sedimentar. Rio de Janeiro: Ed.Bertrand Brasil, 1998.

THORNE, C.R.; TOVEY, N.K. Stability of composite river banks. Earh Surface Processes and Landforms. v.6, p.469-484, 1981.

THORNE, C.R. Process of bank erosion river cannels. Unpublished Ph.D. thesis. School of Environmental Sciences. UEA, Norwick, UK, 1978.447p.

WOLMAN, M. G. Factors influencing erosion of a cohesive river bank. American Journal Science. v.257, p.204-216, 1959. 